\title{
A BIOMEDICINA COMO SISTEMA CULTURAL
}

\author{
Pedro PEREIRA \\ Instituto Politécnico de Viana do Castelo (Portugal) \\ pedropereira@ess.ipvc.pt
}

\section{BIOMEDICINE AS A CULTURAL SYSTEM}

Resumen: Con la valorización social conferida a la biomedicina en las sociedades occidentales actuales, casi podríamos ser llevados a pensar que la biomedicina siempre existió o que antes de ella y más allá de ella no había medicina. Sin embargo, en todas las sociedades las personas movilizan estrategias para combatir la enfermedad y promover la salud. Así, en el presente texto, se pretende sostener que la biomedicina forma parte del paisaje cultural donde se desarrolla y, por consiguiente, no es inocua a las dinámicas culturales. Además de describir las condiciones de emergencia de la biomedicina, se hará un enfoque crítico a la misma, edificada en cuatro ejes fundamentales: la etiología de la enfermedad, el lugar de la enfermedad, la terapia de la enfermedad y la ciencia de la biomedicina. Esta línea argumentativa se concluye en la afirmación de la biomedicina como un sistema cultural.

Abstract: With the social valorization conferred on biomedicine in today's Western societies, we could almost be led to believe that biomedicine has always existed or that before and beyond it there was no medicine. However, in all societies people are mobilizing strategies to combat disease and promote health. Thus, in the present text, it is intended to maintain that biomedicine is part of the cultural landscape where it develops and, consequently, is not innocuous to cultural dynamics. In addition to describing the emergency conditions of biomedicine, a critical approach will be developed, based on four fundamental axes: the etiology of the disease, the place of the disease, the therapy of the disease and the science of biomedicine. This argumentative line concludes with the affirmation of biomedicine as a cultural system.

Palabras clave: Biomedicina. Cultura. Etnocentrismo. Enfermedad. Terapia Biomedicine. Culture. Ethnocentrism. Sickness. Therapy 


\section{Nota inicial}

O epíteto de biomedicina conferido por Atwood Gaines e Robert Hahn (Gaines e Hahn, 1985) sobrepôsse a uma diversidade de outras designações como medicina cosmopolita, medicina Ocidental, medicina alopática ou, apenas, medicina ${ }^{l}$. Apesar do termo biomedicina ser extremamente escorregadio ${ }^{2}$ (Baronov, 2008), apesar da sua maior ou menor ubiquidade (Baronov, 2008; Gaines e Davis-Floyd, 2004: 95), é habitualmente este o termo utilizado no campo da antropologia da saúde para nos referirmos a um determinado tipo de medicina. Com o termo biomedicina, pretende-se fazer referência à medicina profissional Ocidental, enfatizando a sua proeminência biológica (Gaines e Davis-Floyd, 2004: 95), pois esta medicina afirma que a doença é em grande parte causada por desvios de normas biológicas universais (Gaines, 2005).

Com a valorização social conferida à biomedicina nas sociedades ocidentais atuais, quase que poderíamos ser levados a pensar que a biomedicina sempre existiu ou que antes dela e para além dela não havia medicina. Ainda que frequente e etnocentricamente qualificadas como etnomedicinas, em todas as sociedades as pessoas mobilizam estratégias para combater a doença e promover a saúde, tal como aconteceu desde o Próximo Oriente Antigo, III milénio a.C., até ao Ocidente do século XXI.

Assim, no presente texto pretende-se sustentar que a biomedicina, longe de se situar num assético lugar metacultural, faz parte da paisagem cultural onde se desenvolve e, por consequência, não é inócua às dinâmicas culturais. Deste modo, torna-se imprescindível começar por descrever as condições de emergência da biomedicina. Em seguida, apresentar-se-á uma abordagem crítica à biomedicina, edificada em quatro eixos fundamentais: a etiologia da doença, o lugar da doença, a terapia da doença e a ciência da biomedicina.

Esta linha argumentativa conclui-se na afirmação da biomedicina como um sistema cultural.

\section{I - A emergência da biomedicina}

Esta jovem medicina, nascida nos finais do século XVIII (Foucault, 2004-a), é herdeira de uma longa tradição de cura e o parto deu-se num contexto particular. Antes do aparecimento da biomedicina, a medicina era dominada por práticas de cura como a medicina dos humores, a astrologia, a alquimia ou o herbalis$\mathrm{mo}^{3}$. Aliás, até ao final do século XVIII, numa altura em que a maioria das pessoas vivia no meio rural, fora das vilas e das cidades, a maior parte das doenças eram tratadas em casa, mais no meio doméstico do que no domínio público, e principalmente pelas mulheres da família que recorriam à ervanária tradicional como principal método de cura. $\mathrm{O}$ saber destas mulheres, que não era baseado em autores gregos ou latinos, nem estava nos livros, mas sim partilhado cumulativamente e transmitido de geração em geração, efetivava-se na confeção de remédios feitos à base de ervas que elas recolhiam nos seus jardins, nos campos e nos bosques (Worsley, 1997: 186-189).

Algumas dinâmicas foram importantes para o surgimento da biomedicina, nomeadamente o aparecimento do Estado-Nação, o desenvolvimento das ciências naturais e a ascensão profissional da medicina. Com o aparecimento do Estado-Nação passamos a ter uma autoridade central que começa a interessar-se cada vez mais pela saúde da sua população, pois o bem-estar dos seus membros afetava diversos aspetos como a produtividade nacional, o nível de prosperidade, as capacidades de defesa da nação e a taxa de crescimento (Giddens, 2004: 156). O Estado passou a controlar as pessoas, privilegiando a "vigilância" e a "disciplina" para tornar os "corpos dóceis" (Foucault, 2004b), e a sua sexualidade, através do "dispositivo da sexualidade" (Foucault, 1994), bem como a sua saúde. A ideia de saúde pública começou por procurar erradicar 'patologias' para depois alargar a sua dimensão quando o Estado se tornou responsável pela melhoria das condições de vida da população, designadamente no desenvolvimento de redes públicas de água e de saneamento, para proteger os habitantes das doenças; na pavimentação das estradas e atenção às condições de habitação; na regulamentação específica em matadouros e fábricas de produtos alimentares;

\footnotetext{
1 Os autores, referindo-se ao "Domínio da Biomedicina", utilizam a maiúscula na palavra Biomedicina para se referirem à proeminência profissional da etnomedicina das culturas Ocidentais, ainda que reconheçam que esta é apenas uma das diversas etnomedicinas profissionais em que a focalização está associada a uma versão da biologia humana e fisiopatologia (outros exemplos são a medicina chinesa profissional e a ayurvédica) (Gaines e Hahn, 1985: 18). Todavia, como no presente trabalho não se pretende distinguir valorativamente uma medicina de outras utilizar-se-á biomedicina sem maiúscula, e proceder-se-á de igual forma para as outras medicinas.

2 D. Baronov sustenta que o termo biomedicina deve a sua imprecisão ao facto deste termo incluir três esferas ontológicas (empírica, interpretativa e conceptual) que não existem isoladamente e cada uma apresenta uma imagem incompleta da biomedicina (Baranov, 2008, 2009).

3 P. Worsley sustenta que a teoria galénica dos humores dominou os estudos de medicina desde a segunda metade do século II a.C. até ao século XVIII (Worsley, 1997, pp. 184-185).
} 
na regulamentação das práticas funerárias, que constituíam uma ameaça à saúde da população ${ }^{4}$ (Giddens, 2004: 156). Nesta altura começaram a emergir determinado tipo de instituições como as prisões, os asilos, as casas de correção, as escolas e os hospitais que faziam parte do processo de regulamentação, controlo e reforma dos hábitos das pessoas ${ }^{5}$ (Giddens, 2004: 156).

Outro aspeto que contribuiu para o surgimento da biomedicina foi o desenvolvimento das ciências naturais. Peter Worsley salienta que uma ideia revolucionária que ganhou força no século XVII foi a de que o mundo em que vivemos é natural e então, tudo na natureza, incluindo o corpo, poderia ser estudado partindo dos mesmos princípios genéricos e utilizando os mesmos métodos que eram usados para estudar as rochas (Worsley, 1997: 184). Principalmente, a partir do século XIX, através dos avanços nos campos da biologia e da química, deu-se uma elevada valorização da pesquisa empírica, em detrimento dos textos clássicos, o que levou à grande centralidade do laboratório, relativamente ao hospital, no qual também a cirurgia se transformou com a introdução do éter (1847) e com as técnicas de assepsia (Worsley, 1997: 193-194).

A profissão médica beneficiou com o desenvolvimento das ciências naturais e passou a sediar a formação nos hospitais, ao contrário do que existia antes, pois até aos finais do século XVIII o médico visitava pontualmente o hospital (Foucault, 2002). Aliás, na Idade Média, os médicos tinham como doentes os reis e os aristocratas, pois os pobres não tinham dinheiro para os seus serviços, atendendo a que estes médicos queriam ser ressarcidos da sua dispendiosa formação ao longo de catorze anos, e na qual se incluíam não apenas medicina, mas também o estudo dos clássicos (Worsley, 1997: 185).

Contudo, ainda mesmo durante o século XIX, não havia uma grande consideração profissional pelos médicos, por diversos motivos: as suas credenciais eram relativamente fáceis de conseguir; o seu corpo de conhecimento era demasiado pequeno; os seus instrumentos de diagnóstico e terapia eram primitivos e, frequentemente, perigosos ${ }^{6}$; as suas habilidades para curar não eram particularmente impressionantes; e diferentes tipos de médicos tinham ideias muito diferentes sobre as causas e o tratamento das doenças, e competiam pelos doentes e pela legitimidade social. A par disto, deve notar-se que os médicos eram apenas uma pequena percentagem do total de pessoas que praticavam várias artes de cuidar, como: parteiras, endireitas, enfermeiras, farmacêuticos, barbeiros (que faziam pequenas cirurgias), herbalistas, curandeiros religiosos e populares (Freund e Mcguire, 1999: 206).

A partir do início do século XX, os médicos atingiram, de uma forma progressiva, a dominância profissional através de três estratégias: "a eliminação", de parteiras, de clérigos e de barbeiros cirurgiões, que foram expulsos definitivamente das suas práticas legítimas; "a cooptação", de homeopatas e de osteopatas, que eram competidores profissionais; e "a subordinação", de enfermeiras, de farmacêuticos, de anestesistas, de técnicos de raio-X e de todos os profissionais de saúde que com eles competiam, podendo desta forma adquirir um estatuto de legitimidade para exercer o monopólio no mercado do sistema de saúde ${ }^{7}$ (Freund e Mcguire, 1999: 206).

Chegados ao século XXI, temos uma profissão médica que se apresenta claramente autónoma, que controla o recrutamento e a formação de novos profissionais e licencia aqueles que podem exercer medicina, que extravasou a sua influência para as mais diversas esferas da vida humana, desde o parto até à morte, $\mathrm{e}$ que se constitui como o único grupo de terapeutas curandeiros que possui legitimidade legal para atestar a veracidade da doença.

\section{II - As características e as críticas à biomedicina}

\section{1 - A etiologia da doença: a causa ou as múltiplas causas}

\section{1 - A causa da doença}

Na sua clássica obra, The Mirage of Health (1959), René Dubos defende que até ao final do século XIX a doença era vista como a falha na harmonia entre a pessoa e o seu ambiente (Dubos, 1987: 101). Mas com

\footnotetext{
4 Sobre este assunto, no caso português, particularmente a oposição ao enterramento em cemitérios públicos, veja-se o artigo de J. Pina Cabral e R. G. Feijó, "Um Conflito de Atitudes Perante a Morte: A Questão dos Cemitérios no Portugal Contemporâneo" (Cabral e Feijó, 1985).

5 Sobre instituições com missões mais carcerárias, ver o conceito de "instituição total”, de E. Goffman (1987), na sua obra Aylums (1961). Estas características estiveram claramente presentes em hospitais de saúde mental (manicómios) e algumas delas continuam a estar presentes em hospitais gerais.

6 Relativamente às terapias, notem-se alguns exemplos: sangrias, purgações, vómitos, uso de drogas, como o ópio, e venenos, como o mercúrio e o arsénio.

7 Relativamente aos saberes e poderes dos médicos em Portugal, veja-se particularmente o trabalho de G. Carapinheiro (1993), Saberes e Poderes no Hospital - Uma Sociologia dos Serviços Hospitalares. Veja-se também a estimulante abordagem antropológica à profissão médica feita por M.S. Queiroz (1991), "Perspectivas teóricas sobre medicina e profissão médica: uma proposta de enfoque antropológico".
} 
os trabalhos de investigadores como Pasteur ou Koch, a etiologia da doença tornou-se menos relacional e mais concreta, pois cada doença teria como causa um microrganismo virulento específico, um agente específico (como um parasita, um vírus ou uma bactéria), que produziria também uma doença específica. Esta conceção da doença ficou conhecida como "doutrina da etiologia específica" (Dubos, 1987) e expandiuse das "doenças infecciosas" para as "doenças de carência", nas quais a etiologia específica era a falta de algum elemento necessário, como por exemplo uma vitamina ou uma hormona (Freund e Mcguire, 1999: 213). A importância desta teoria está bem patente nas palavras de R. Dubos: "inquestionavelmente, a doutrina da etiologia específica tem sido a força mais construtiva na pesquisa médica há quase um século e as conquistas teóricas e práticas a que levou constituem o grosso da medicina moderna" (Dubos, 1987: 102).

A intocabilidade desta teoria é levada ao limite da pesquisa científica e traduzida no conceito idiopático. Mesmo que não seja possível uma influência causal específica, o facto clínico designa-se idiopático e continua a ter uma causa, que ainda não foi descoberta (Helman, 2003: 110).

\section{2 - As múltiplas causas da doença}

Apesar da doutrina da etiologia específica, através da aproximação experimental, ter sido extremamente efetiva para a descoberta de agentes da doença e para o estudo de algumas das suas características, particularmente no que diz respeito a doenças infeciosas, até agora "poucos foram os casos nos quais se alcançou um relato completo das causas da doença"; apesar dos esforços frenéticos, as causas do cancro, arteriosclerose, desordens mentais e outros grandes problemas médicos do nosso tempo continuam por descobrir (Dubos, 1987: 102).

De facto, o caráter permanente das doenças crónicas, dominantes no Ocidente, faz pensar na fragilidade da etiologia específica, bem como no respetivo tratamento específico, suportado na fé na indústria farmacêutica, que mais tarde ou mais cedo encontraria a "bala mágica" que mataria qualquer doença. Passamos então de uma etiologia específica para a multicausalidade das doenças pois, parafraseando Dubos, "todos os distúrbios patológicos são o somatório de uma multiplicidade de interacções entre o ambiente externo e interno" (Dubos, 1987: 123). Portanto, ainda que o agente seja necessário, não é suficiente para causar a doença, pois esta não é o resultado de apenas um facto, mas de muitos fatores que contribuem para a complexa rede de causalidade, em que intervêm três elementos principais: o agente, mas também o hospedeiro e o ambiente (Freund e Mcguire, 1999: 12-13). Neste ambiente biossocial em que interagem o agente e o hospedeiro estão naturalmente presentes condições que os aproximam, como por exemplo a insalubridade, que se pode traduzir na ingestão de água contaminada. No entanto, isto não significa necessariamente doença, pois é preciso ter em atenção o estado fisiológico, a relativa imunidade do hospedeiro, do indivíduo ${ }^{8}$.

\section{2 - O lugar da doença: o corpo ou para além do corpo}

\section{1 - O corpo}

No modelo tecnocrático ${ }^{9}$ da medicina (Davis-Floyd e St. John, 2001), vigora aquilo que as mesmas chamam o princípio da separação, ou seja "as coisas são melhor compreendidas fora do seu contexto, isto é, separadas dos objectos e pessoas relacionadas" (Davis-Floyd e St. John, 2001: 17). Assim, este modelo, alicerçado na acentuada centralidade que atribui ao corpo, separa-o da pessoa, depois de já ter separado esta do seu contexto sociocultural. Em seguida, entra no corpo guiado por um código de leitura mecanicista para encontrar a doença.

Diversos autores (Engel, 1977; Freund e Mcguire, 1999; Nettleton, 1999; Helman, 2003) salientaram o reducionismo da biomedicina, que se caracteriza por excluir as dimensões psicológicas, sociais e culturais do indivíduo em situação de doença e que, como sustenta Arthur Kleinman, em última análise poder ser desumanizante (Kleinman, 1995: 31).

Desta forma, ao reduzir o corpo à sua biologia ${ }^{10}$, a biomedicina previne-se das conceções sociais e simbólicas do corpo, bem como das consequências das condições sociais nas situações de saúde, doença e tratamento ${ }^{11}$.

Liberta desta indumentária social e cultural, a biomedicina aprimora o reducionismo, separando a mente do corpo. O dualismo corpo-mente, como é referido por vários autores (Engel, 1977; Freund e Mcguire, 1999; Nettleton, 1999; Davis-Floyd e St. John, 2001; Helman, 2003; Queiroz, 2003), pressupõe que os males psicossomáticos são mentais e devem ser tratados pela psiquiatria (Queiroz, 2003: 122) e a (bio)

8 Dubos alerta para a importância das causas predisponentes, precipitantes e perpetuantes (Dubos, 1987: 107).

9 Os autores em causa sustentam que "tecnocrática é a sociedade que é hierarquizada, burocratizada e organizada em torno de uma ideologia de progresso tecnológico" (Davis-Floyd e St. John, 2001: 16).

10 Como refere A. Kleinman, "na definição biomédica, a natureza é física" (Kleinman, 1995: 30).

11 Vejam-se as consequências da coisificação do corpo, apresentadas com detalhe por R. Bologh (Bologh, 1981). 
medicina ocupa-se do corpo.

A fundação filosófica desta dicotomia entre corpo e mente talvez possa fazer-nos recuar até René Descartes (1977) e à sua obra Discours de la méthode (1637). Contudo, as mudanças na medicina estarão na observação clínica no fim do século XVIII e na anatomia patológica iniciada no século XIX (Freund e Mcguire, 1999: 212). Enquanto até ao fim do século XVIII os médicos viam o corpo indiretamente, através das descrições que os doentes faziam da sua experiência de doença, a partir desta altura desenvolveu-se o "olhar clínico" (Foucault, 2004-a) que permitiu aos médicos, auxiliados pelos desenvolvimentos tecnológicos (estetoscópio, 1819), aceder diretamente (presumivelmente de uma forma objetiva e neutra) aos sinais e significados da doença, através deste olhar que a decifra.

A par disto, com o desenvolvimento da anatomia patológica as doenças eram concetualizadas como alterações nos tecidos que eram visíveis nos corpos abertos, nomeadamente durante as autópsias ${ }^{12}$. Esta forma de localização da doença no corpo teve naturalmente consequências na separação entre o corpo e a mente e acentuou esta dicotomia nas práticas médicas.

Com o olhar clínico e com a anatomia patológica o corpo franqueou a entrada e, finalmente, tornou-se possível encontrar as doenças físicas localizadas, presumivelmente, dentro do corpo (Engel, 1977). Contudo, é preciso decifrar este espaço labiríntico do corpo e a metáfora encontrada pela biomedicina foi a de conceber o corpo como uma máquina (Freund e Mcguire, 1999; Nettleton, 1999; Davis-Floyd e St. John, 2001; Queiroz, 2003). Partindo desta conceção mecanicista do corpo ${ }^{13}$, a biomedicina desenvolveu especializações para cada um dos componentes da máquina, enfatizando sistemas individuais ou órgãos e excluindo uma imagem da totalidade do corpo. Neste processo de especialização, a pessoa é vista como um somatório de diversas partes (Queiroz, 2003: 122) e a doença é um distúrbio que decorre do mau funcionamento de algum dos seus componentes que "os médicos, quais engenheiros, podem reparar o que está disfuncional" (Nettleton, 1999: 3) ou mesmo substituir, através do transplante de órgãos, pacemakers, implantes ou articulações artificiais.

\section{2 - Para além do corpo}

Sobretudo nos últimos três séculos, a biomedicina foi-se progressivamente modificando, deixando de ser dominantemente uma medicina de casa (até aos fins do século XVIII), na qual o discurso do doente era mais valorizado, para passar a ser uma medicina de hospital (fins do século XIX), na qual o discurso do médico era mais valorizado, para na atualidade ser uma medicina de laboratório, na qual o discurso tecnológico é mais valorizado. Subjacente a este processo de mudança, e na sua procura incessante de chegar à verdade da doença, a biomedicina foi delineando um discurso tão verdadeiro quanto a própria doença, alicerçado na reificação ${ }^{14}$ quer do corpo quer da doença, que se foi depurando de todos os atritos que pudessem desviá-la do caminho em direção à etiologia da doença. Ancorada numa pretensa objetividade, a biomedicina vai isolando a pessoa do seu contexto social e cultural, vai desvalorizando o seu discurso, afastando a sua mente para se poder focalizar no seu corpo, uma máquina organizada em várias partes. Será, portanto, num destes componentes que se ocultará a doença, e que através da mais sofisticada tecnologia que incide sobre o corpo, ou da recolha de um fragmento do corpo para analisar num laboratório, se descobrirá a sua etiologia.

Esta excessividade biológica, designação proposta para se fazer referência ao reducionismo biológico aquando da abordagem da pessoa doente, foi denunciada desde os anos setenta do século XX. Kleinman, Eisenberg e Good, no seu clássico artigo "Culture, illness and care: Clinical lessons from anthropological and cross-cultural research" (1978), sustentam que a perspetiva biomédica pressupõe que as preocupações biológicas são mais básicas, 'reais', clinicamente mais significativas e interessantes do que as questões psicológicas e socioculturais (Kleinman, Eisenberg, e Good, 1978: 255). Engel vê nesta acentuada valorização das dimensões físicas da doença uma evidência de uma característica do modelo biomédico, a "dualidade mente-corpo", (Engel, 1977: 130), que leva o médico a centrar-se na procura de anomalias físicas, reduzindo a pessoa a um conjunto de parâmetros fisiológicos anormais. Alimentada pelos desenvolvimentos tecnológicos de diagnóstico, que permitem revelar mudanças nos níveis celular, bioquímico e molecular e localizar exatamente a patologia numa parte do corpo humano, o foco da biomedicina incide menos sobre o doente real e focaliza-se num determinado órgão, sistema, grupo de células ou numa parte corporal do

12 Veja-se particularmente o capítulo VIII, “Abram-se alguns cadáveres”, da obra Naissance de la clinique (1963), de M. Foucault (2004-a, pp. 136-162).

13 Sobre a perspetiva mecanicista da medicina ocidental, veja-se o olhar antropológico apresentado por M.S. Queiroz, 1986, "O paradigma mecanicista da medicina ocidental moderna: uma perspectiva antropológica”, Revista de Saúde Pública, 20 (4), pp. 309-317.

14 Utiliza-se aqui o conceito de reificação no sentido proposto por Berger e Luckman: “a reificação é a apreensão dos fenómenos humanos como se fossem coisas, isto é, em termos não humanos ou até sobre-humanos” (Berger e Luckman, 1999: 98). 
doente (Helman, 2003: 112).

À excessividade biológica, a biomedicina associa um outro dogma, que aqui se propõe chamar literalidade do corpo. Com este conceito, pretende-se fazer notar o quanto é frágil conceber o corpo higienizado de todo o seu aparato simbólico, sendo a biologia do corpo a sua realidade última. Importa começar por salientar que a biologia mecanicista que caracteriza a biomedicina não é universal. Outras medicinas baseadas na medicina, como as medicinas profissionais da Índia, da China e do Japão, apresentam outras analogias biológicas, levando Gaines a avançar com a noção de "biologias locais" (Gaines, 1992: 190). Reforçando o que foi referido, vale a pena invocar o conhecido artigo de Nancy Scheper-Hughes e Margaret Lock, "The mindful body: a prolegomenon to future work in medical anthropology" (1987), no qual as autoras sustentam que a perspetiva cartesiana de conceber o corpo, separando-o da mente, é uma "tradição epistemológica cultural e historicamente construída e que não é universalmente partilhada" (Scheper-Hughes e Lock, 1987: 6). As mesmas autoras partem do pressuposto de conceber "o corpo como simultaneamente um artefacto físico e simbólico, como igualmente natural e culturalmente produzidos e ancorado num determinado momento histórico" (Scheper-Hughes e Lock, 1987: 6-7). Superando o dualismo cartesiano, as autoras propõem três perspetivas a partir das quais o corpo pode ser visto: corpo individual, corpo social e corpo político (Scheper-Hughes e Lock, 1987).

A centralidade redutora do biologismo biomédico concebe o "paciente como objeto" (Davis-Floyd e St. John, 2001) desvalorizando o seu discurso. Note-se que uma das primeiras tarefas dos alunos de medicina é a dissecação humana, tornando claro que o seu objeto de estudo é o corpo e não a pessoa (Nettleton, 1999: 6). Esta reificação do corpo da pessoa pode conduzir, no limite, à quase dispensabilidade do indivíduo, desde que possam ser recolhidos fragmentos do corpo do doente, física ou virtualmente. Podem emergir aquilo que Cecil Helman designa como "pacientes de papel", e que se expressa nas tiras de papel dos eletroencefalogramas e eletrocardiogramas, nas chapas de raios X e nos relatórios de exames ao sangue, bem mais fáceis de interpretar, quantificar e controlar e que se podem tornar "tão ou mais interessante do que os próprios pacientes de verdade" (Helman, 2003: 92) ${ }^{15}$. Talvez nos aproximemos daquilo a que se poderá chamar doentes virtuais, que será a representação virtual do doente, recorrendo a todo o campo informático e da imagiologia ${ }^{16}$. O papel será poupado como já havia sido poupada a pessoa que se transformou em paciente e cada vez mais em cliente.

Esta perceção do doente centra-se na biologia e desvaloriza o discurso do doente, centra-se no indivíduo e desvaloriza o discurso da família. Mas, como lembra Thomas Csordas, "antes que os antropólogos e pesquisadores clínicos começassem a entender a importância dos relacionamentos paciente-médico e o vasto poder do efeito placebo era comum pensar que os tratamentos biomédicos eram eficazes independentemente daquilo que o paciente experienciasse" (Csordas, 2010: 31). Atendendo ao que foi dito sobre a literalidade do corpo compreende-se que esta possa conduzir a que "cada vez mais, a biomedicina tem afastado a experiência da doença como um legítimo objecto de interesse clínico" (Kleinman, Eisenberg, e Good, 1978: 252). Ou seja, nem a forma como o doente experiencia a doença nem as suas opiniões sobre a etiologia e decurso da mesma são valorizadas pelo médico ${ }^{17}$. Aliás, a relação, através da entrevista, entre o médico e o doente pode transformar-se, frequentemente, naquilo que James Thompson designa como uma "fastidiosa inter-relação entre o médico e a doença" (Thompson, 1984: 87).

Contudo, como mostra A. Kleinman na sua obra Patients and Healers (1981), para promover o bem-estar do doente é fundamental contrapor o modelo explicativo do médico ao modelo explicativo do doente (e da sua família). Aliás, como refere Ray Fitzpatrick, quando aborda os "conceitos leigos de enfermidade"18, as interpretações que os doentes fazem dos seus sintomas estão governadas por conceitos e ideias de considerável complexidade e variabilidade (Fitzpatrick, 1984: 31). Em alguns casos, o mesmo nome de uma enfermidade ou sintoma particular não tem a mesma associação para pessoas leigas e médicos, mesmo que ambos usem o mesmo termo corretamente; ou podem referir-se à mesma coisa mas dando-lhe diferentes significados (Lewis, 1980) ${ }^{19}$.

Portanto, "enquanto os antropólogos tentam compreender a percepção que o doente tem da realidade

15 G. Carapinheiro exemplifica este reducionismo relatando um episódio de terreno em que vários médicos se reuniram à volta de uma cama vazia analisando o processo de um doente (Carapinheiro, 1993: 106). Num trabalho que me foi entregue (em 2005) por um grupo de alunos do Curso de Licenciatura em Enfermagem, os autores do mesmo relatam a forma profundamente metonímica que o médico usou para se referir a um doente: "onde está a maca do quisto?".

16 Sobre a computorização da medicina veja-se o trabalho de C. Waldby referente ao Visible Human Project (Waldby, 1997).

17 Como sustenta E. Challinor, este processo de alienação será ainda mais intenso quando a pessoa que recebe cuidados não partilha a cultura do cuidador, como acontece com imigrantes (Challinor, 2011: 490).

18 Ao longo deste capítulo, utilizar-se-á o conceito de enfermidade como correspondência ao conceito inglês de illness. O conceito de doença será reservado para a tradução do conceito inglês disease.

19 Para se conhecer melhor a perspetiva do doente, veja-se o artigo de D. Armstrong, "The patient's view", particularmente a diferença entre aquilo que é ouvido e aquilo que é dito (Armstrong, 1984). 
clínica, os médicos tentam encaixar a experiência do doente em sintomas objectivos de modo a que esta transformação lhes permita tomar as decisões adequadas no domínio biomédico" (Pfifferling, 1980: 197). Mas, como referem Byron e Mary-Jo D. Good, "os sintomas são significativamente irredutíveis" (Good e Good, 1980: 191), não refletindo anomalias somáticas de uma forma simples e as relações entre sintomas não espelham um conjunto de relações mecânicas e fisiológico-funcionais (Good e Good, 1980: 191).

Contudo, ainda que desvalorize o seu discurso, a biomedicina centra as suas atenções no indivíduo, ou melhor no seu corpo, desvalorizando tudo o que o envolve, como a família e comunidade (Helman, 2003: 109) e abstrai-se dos factores socioculturais e políticos no processo saúde/doença" (Queiroz, 2003: 122); no fundo, como defende Engel, não há espaço para as dimensões psicológicas e sociais da enfermidade (Engel, 1977). A despeito disso, e parafraseando Marc Augé, no seu texto "Ordre biologique, ordre social: la maladie forme élémentaire de l'évenement": "a doença é, simultaneamente, o mais individual e mais social dos eventos" (Augé, 1994). Aliás, em diversas sociedades o social sobrepõe-se ao individual, veja-se o caso do Congo, retratado por Peter Worsley, no qual o diagnóstico e terapia da doença são acentuadamente sociais ${ }^{20}$ (Worsley, 1997: 184).

Assim, por um lado, torna-se fundamental ir para além da biologia e procurar no contexto social e cultural influências no aparecimento de doenças ou aflições nas pessoas. Os padrões de mortalidade e morbilidade ou de 'oportunidades de vida' das pessoas estão relacionados com as estruturas sociais e variam de acordo com o género, classe social, 'raça' e idade. Por conseguinte, o modelo biomédico falha quando não tem em conta as desigualdades sociais na saúde ${ }^{21}$. Se tomarmos como exemplo, apontado por Robbie Davis-Floyd, a mortalidade resultante do nascimento, que é amplamente reconhecida como um massivo problema global, a biomedicina identifica como causas maiores para a morte materna a hemorragia e a toxemia. Porém, o olhar antropológico para o mesmo fenómeno, em países com altas taxas de mortalidade materna, faz sobressair aspetos que extravasam a biologia, como altas taxas de uma generalizada saúde pobre das mulheres, que sofrem de excesso de trabalho, exaustão, anemia, má nutrição, e de uma diversidade de doenças resultantes da água poluída. Daí resulta que o mais importante para o desenvolvimento da saúde das mulheres e para a segurança do nascimento é a água limpa, a nutrição adequada e a melhoria das oportunidades económicas para as mulheres (Davis-Floyd, 2005).

Por outro lado, ao contrário daquilo que é defendido pela biomedicina, as interpretações e os significados subjetivos relativos à doença, ao tratamento e à saúde, são claramente relevantes na compreensão das aflições do doente, bem como nos processos de restituição da saúde. Daí o surgimento de modelos mais humanistas, como por exemplo a "perspetiva bio-psico-social" de G. Engel (Engel, 1977), o "modelo explicativo" de A. Kleinman (Kleinman, 1981), o "modelo cultural hermenêutico" de Byron e Mary Jo Good (Godd e Good, 1980) e o "modelo humanístico da medicina" de Robbie Davis-Floyd e Gloria St. John (Davis-Floyd e St. John, 2001).

\section{3 - A terapia da doença: dimensões e estratégias}

\section{1 - Os sucessos, o exagero da eficácia e os efeitos secundários}

Apesar das críticas do exagero da sua eficácia ou dos seus efeitos secundários, os sucessos da biomedicina, particularmente ao longo do século $\mathrm{XX}^{22}$, são de uma dimensão bastante alargada, o que contribuiu seguramente para o desenvolvimento da saúde de uma forma geral, podendo destacar-se quer a erradicação, praticamente, das principais doenças infeciosas fatais na maioria dos países do Ocidente, como a varíola, a difteria, a pólio, o tétano, o sarampo e muitas infeções bacterianas; quer a diminuição da mortalidade infantil, assim como a mortalidade de mulheres por parto e a esperança de vida aumentou (Helman, 2003: 93); quer, ainda, o desenvolvimento das técnicas cirúrgicas, utilizando tecnologias cada vez mais sofisticadas (microcirurgia, cirurgia com ultrassom, etc).

Fora do Ocidente, a biomedicina apresenta toda uma série de sucessos espetaculares através da eliminação da varíola, malária, tuberculose ou febre-amarela e pela implantação em países como a Índia e o Japão que têm hoje uma acentuada dominância da medicina Ocidental (Worsley, 1997: 225-226).

Uma das principais críticas que foram feitas à biomedicina nos anos setenta foi a exacerbação da sua eficácia. Dois nomes e duas obras encabeçam este tipo de críticas: Thomas McKeown, The Modern Rise of Population (1976) e Ivan Illich, Medical Nemesis: The Expropriation of Health (1975). Ambos põem em causa que a medicina tenha sido determinante nomeadamente no declínio da taxa de mortalidade e os dois apresentam o exemplo da tuberculose. Aliás, Illich vai ainda mais longe ao começar o capítulo introdutório

20 Veja-se particularmente o subcapítulo "Kongo Medicine: The Quest for Terapy” (Worsley, 1997, pp. 171-184).

21 Sobre este assunto, veja-se a perspetiva de Sarah Nettleton, "Social Inequalities and Health Status", The Sociology of Health \& Illness (Nettleton, 1999, pp. 160-193).

22 Note-se que os sucessos da biomedicina continuaram neste início do século XXI. 
da referida obra com a seguinte afirmação: "A organização médica ameaça a saúde” (Illich, 1977: IX). E reforça a mesma ideia um pouco mais à frente: "A organização médica tornou-se um dos maiores perigos para a saúde" (Illich, 1977: 4). Para este autor, os determinantes no estado de saúde de uma população eram: em primeiro lugar "a alimentação, condições de habitação e de trabalho, a coesão das relações sociais e os mecanismos culturais que permitem manter a estabilidade da população (que desempenham o papel decisivo do estado de saúde dos adultos e da idade em que têm tendência a morrer)" (Illich, 1977: 12); depois as atividades sanitárias, e, por fim, o impacto do ato médico sobre a saúde global (Illich, 1977: 13-16).

Relativamente ao declínio da mortalidade, T. McKeown (1976), baseando-se em dados demográficos da Inglaterra e do País de Gales, sustenta que o declínio da mortalidade que ocorreu nas sociedades Ocidentais deveu-se mais a outros fatores (mudanças sociais e ambientais) do que à intervenção médica (vacinas, tratamento ou outros modos de intervenção médica ${ }^{23}$. Estes fatores seriam a maior disponibilidade de alimentos (melhor nutrição), serviços de saneamento mais eficazes, canalização da água (disponibilidade de água potável), melhorias na higiene, controlo da natalidade. Illich corrobora com esta ideia ao afirmar que:

"seria um erro grave explicar as transformações das taxas globais de mortalidade por um progresso também global da eficácia do acto médico. A diferença entre a esperança de vida de gerações sucessivas aparece no Antigo Regime sem que tenha havido progressos terapêuticos notórios nessa época. Amplifica-se com a revolução pasteuriana e desvanece-se bastante antes do aparecimento do arsenal da medicina contemporânea" (Illich, 1977: 10) ${ }^{24}$.

Se tomarmos como exemplo a tuberculose, também se nota proximidade entre os dois autores. McKeown reportando-se ainda à Inglaterra e ao País de Gales, desde que começou a ser registada a causa da morte (1838) até aos anos 70 do século XX, salienta que apesar de o bacilo da tuberculose ter sido identificado por Koch em 1882, todavia os tratamentos não tiveram influência significativa até ao início do século XX. O tratamento em escala substancial (vacina BCG) iniciou-se em Inglaterra em 1954, mas 57\% do declínio da tuberculose teve lugar antes do século XX. Não há nenhuma dúvida sobre o contributo da quimioterapia, que foi responsável pela rápida queda da taxa de mortalidade, resultante da doença, desde 1950. No entanto, sem esta intervenção a taxa de mortalidade continuaria a descer, mas mais lentamente (Mckeown, 1995: 183). Illich apresenta o exemplo da tuberculose em Nova Iorque. "Em New York a mortalidade era

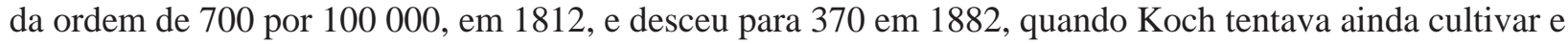
corar o primeiro bacilo. Mesmo continuando a tuberculose a ocupar o $2^{\circ}$ lugar nas causas de morte, a taxa de mortalidade já tinha descido para 180 quando em 1910 se abriu o primeiro sanatório. Depois da Segunda Guerra Mundial, antes da utilização dos antibióticos, havia já passado para o $11^{\circ}$ lugar com um índice de mortalidade de 48 por 100000 (Illich, 1977: 11) ${ }^{25}$.

O exagero da eficácia da biomedicina pode também ser notado nas franjas das doenças curadas, ou seja, as doenças crónicas. Doenças cardiovasculares, a diabetes e o cancro entre outras doenças crónicas, algumas delas degenerativas, para as quais não há cura, apresentam uma grande dimensão nos países Ocidentais. Naturalmente que à falibilidade da biomedicina deve ser acrescentado o contributo dos estilos de vida, bem como os padrões de consumo que seguramente contribuem para o surgimento e continuidade deste tipo de doenças.

Paralelamente aos sucessos e ao exagero da eficácia da biomedicina situam-se os seus efeitos secundários $^{26}$. Se se tivesse que fazer convergir para um autor as críticas mais contundentes ao impacto negativo da

23 Este professor de medicina social considera na sua análise o período desde 1839, quando começou a ser registada a causa de morte, até 1935.

24 P. Worsley recupera as ideias de Mckeown, para sustentar que as mudanças sociais e económicas, especialmente o melhoramento das casas, educação e limitações familiares, juntamente com a reforma sanitária (saneamento e tratamento da água) foram mais importantes para reduzir a suscetibilidade de doenças do que profilaxias como a vacinação ou mudanças na organização da medicina, particularmente as doenças de crianças - como difteria, sarampo, coqueluche, tuberculose e poliomielite (Worsley, 1997: 204). Refira-se ainda que num artigo publicado em 1977, "The Questionable Contribution of Medical Measures to the Decline of Mortality in the United States in the Twentieth Century", John B. Mckinlay e Sonja M. Mckinlay, chegaram a conclusões semelhantes às de McKeown, mas relativamente aos Estados Unidos, nas suas palavras: "No geral, as medidas médicas (quimioterapêuticas e profiláticas) parecem ter contribuído pouco para o declínio global da mortalidade nos Estados Unidos desde meados de 1900" (Mckinlay e Mckinlay, 1977: 425).

25 A. Giddens, reportando-se aos contributos genéricos das ações biomédicas, afirma que os "fármacos, os avanços no campo da cirurgia e os antibióticos só passaram a influenciar de forma significativa as taxas de mortalidade nas últimas décadas. Os antibióticos usados para tratar as infecções bacterianas apareceram nos anos trinta e quarenta do século XX, enquanto as vacinas (contra doenças como a poliomielite) foram desenvolvidas mais tarde" (Giddens, 2004: 157-158). P. Worsley vai mais longe, ao afirmar que "muitos sucessos dos medicamentos foram precedidos por medidas preventivas" (Worsley, 1997: 227).

26 A este propósito, veja-se a revista Journal of Negative Results in BioMedicine que tem como objetivo publicar todos os aspetos 
biomedicina, seria naturalmente para Ivan Illich. A sua obra, Nemesis: The Expropriation of Health (1975), é um tratado diversificado de críticas à biomedicina. I. Illich anuncia, desde logo, na Introdução:

"a medicina torna-se uma oficina de reparação e manutenção destinada a conservar em estado de funcionamento o homem gasto por uma produção desumana" (Illich, 1977: X). Um pouco mais à frente, Illich considera que "o impacto negativo da organização médica constitui uma das epidemias mais invasoras do nosso tempo" (Illich, 1977: 23).

É neste contexto que I. Illich apresenta o seu conceito de "doença iatrógena", defendendo que esta "engloba todas as condições clínicas cujos agentes patogénicos são os medicamentos, os médicos ou os hospitais" (Illich, 1977: 24). A iatrogénese pode ter uma expressão clínica, apresentando-se como a "multidão de efeitos secundários mas directos da terapêutica" (Illich, 1977: 24), nomeadamente medicamentos, a isto I. Illich chama "iatrogénese clínica". Um bom exemplo deste tipo de consequências da ação médica é o caso da Talidomida. Nos anos sessenta, do século XX, esta substância foi administrada a grávidas e oito mil mulheres deram à luz crianças com membros curtos ou mesmo sem eles. Podemos acrescentar a este exemplo, os dados apresentados por Cecil Helman, que indicam que cerca de $6 \%$ dos pacientes hospitalizados nos Estados Unidos são infetados por bactérias resistentes a antibióticos (Helman, 2003: 94).

Para além da expressão clínica da iatrogénese, esta apresenta outras dimensões, nomeadamente o facto de tornar as pessoas mais dependentes dos especialistas médicos, portanto mais desqualificadas para lidar com as mais diversas situações de doença, naquilo a que I. Illich chama "iatrogénese social"; e o facto de promover a destruição do potencial cultural das pessoas e das comunidades para lidar de uma forma autónoma com a enfermidade, a dor e a morte, naquilo a que I. Illich designa como "iatrogénese estrutural" (Illich, 1977: 123-204).

\section{2 - O imperativo tecnológico e os seus custos}

É clara a sobrevalorização que o modelo biomédico confere à tecnologia (Davis-Floyd e St. John, 2001), traduzindo-se isto naquilo a que Barbara Koenig (Koenig, 1988) chama "imperativo tecnológico", e que se expressa bem na dominância da tecnologia na descoberta e no tratamento da doença. A tecnologia permite ao médico ocultar-se atrás da máquina, afastando-se do paciente e também desresponsabilizar-se ${ }^{27}$. Como refere Helman, "na medicina contemporânea (...) o processo de diagnóstico foi-se distanciando cada vez mais dessa coleta de informações subjectivas e clínicas (colhidas ao olhar, ouvir, tocar e sentir) para aproximar-se do uso de informações teoricamente objectivas ou 'paraclínicas' (colhidas por aparelhos de tecnologia de diagnose). As anormalidades podem então ser detectadas por essas máquinas em nível celular, bioquímico ou ainda molecular, mesmo quando os pacientes não têm quaisquer sintomas nem qualquer sensação subjectiva de que possa haver nada de errado consigo" (Helman, 2003: 92).

Ora, a centralidade da tecnologia, encerrada no hospital, resulta em elevados custos do sistema de saúde, apresentando-se como uma das principais críticas à biomedicina (Kleinman, Eisenberg, e Good, 1978) ${ }^{28}$. No caso português, o Pordata é bem ilustrativo dos imparáveis custos com a saúde ${ }^{29}$. Contudo, toda esta "medicalização do orçamento" (Illich, 1977: 45) não tem tido o retorno correspondente. Ainda que, a partir da segunda metade do século XX, a alocação em recursos no campo médico tenha aumentado enormemente nos países desenvolvidos, os ganhos em saúde têm sido "pouco significativos" (Queiroz, 1986). Na sua forma sempre acutilante, I. Illich ao constatar que o nível de saúde não melhora ao passo que aumentam as despesas médicas aponta uma de duas conclusões: "a ineficácia global e crescente da organização médica" ou a "sociedade tornou-se rapidamente mais enferma" (Illich, 1977: 39). ${ }^{30}$

inesperados, controversos, provocadores e/ou resultados/conclusões negativos no contexto dos princípios atuais, com sustentação clínica e experimental.

27 Note-se, contudo, que esta perspetiva não é consensual. Bjørn Hofmann, no seu artigo, "Is there a technological imperative in health care?", discute de uma forma crítica, a relação entre o uso de tecnologia e a desresponsabilização dos médicos, e sustenta que nenhuma tecnologia isenta os médicos de responsabilidade na prestação de cuidados de saúde (Hofmann, 2002).

28 Para além da tecnologia, outros elementos contribuem para aumentar as despesas dos hospitais e dos cuidados de saúde em geral, como os medicamentos, as burocracias médicas, os salários das equipas de funcionários, a formação, os litígios e o seguro contra erro médico (Helman, 2003: 93). Neste campo dos custos com a saúde, não devem ser descurados os fins lucrativos (DavisFloyd e St. John, 2001) que presidem à criação e manutenção, concretamente, de hospitais privados.

29 M. Queiroz denuncia a irracionalidade deste tipo de medicina dispendiosa, baseada no hospital e na alta tecnologia, especificamente em países como o Brasil, onde a grande maioria da população é subalimentada (Queiroz, 1986: 313).

30 Veja-se com mais detalhe as despesas estatais com a saúde em diversos países, naquilo que I. Illich designa "A medicalização do Orçamento" (Illich, 1977, pp. 38-45). 


\section{3 - A medicalização da vida}

Se é certo que a biomedicina deu continuidade às variadas estratégias de disciplina e vigilância do corpo nas suas mais diversas dimensões (Foucault, 2004-b), não é menos verdade que as suas ações extravasaram o corpo do indivíduo e alargaram-se até às suas dimensões sociais, naquilo que I. Illich (1977) chamou iatrogénese social. Centrada na sua desenvolvida tecnologia, a biomedicina tornou-se capaz não apenas de antecipar a vida, mas também de a prolongar. No caso do nascimento, as transformações foram acentuadas, pois o parto tornou-se hospitalizado e masculinizado. Reportando-se à Grã-Bretanha, Ann Oakley, na sua obra, The captured womb - A history of the medical care of pregnant women, refere que desde o fim do século XIX a gravidez passou da sua centralidade na comunidade, centrada na mulher, para o hospital, dominado pelos obstetras, homens. Segundo ela, esta mudança não trouxe melhorias na saúde, trouxe um maior controlo sobre o corpo e os estilos de vida das mulheres (Oakley, 1986). No caso americano, Robbie Davis-Floyd, na sua obra, Birth as an American Rite of Passage, particularmente no capítulo, "The Technocratic Model: Past and Present", salienta que este modelo tecnocrático de nascimento concebe o corpo feminino como uma máquina defeituosa e perpetua a inferioridade da mulher em relação ao homem (DavisFloyd, 1992: 44-72).

A morte, vista como uma derrota para a biomedicina (Davis-Floyd e St. John, 2001), abandonou a casa e a comunidade para se encerrar no hospital, no qual, perante a impossibilidade de ser evitada é adiada. Portanto, de "domesticada" a morte transformou-se em "interdita", passando do leito de casa em redor da família para o leito do hospital em redor de médicos e enfermeiros e de toda a tecnologia que serve a biomedicina (Ariès, 1989).

A par do nascimento e da morte, diversos comportamentos considerados desviantes passaram a ser medicalizados. Por conseguinte, através deste processo de medicalização problemas não médicos passam a ser definidos e tratados como problemas médicos, frequentemente usando os termos de doenças ou desordens (Conrad, 1992: 209) ${ }^{31}$. Os exemplos são diversos, como a atividade das crianças, o cansaço, a depressão, o crime, a homossexualidade ou a loucura. ${ }^{32}$

\section{4 - A biomedicina como ciência}

Assente no positivismo da ciência, a biomedicina procura a objetividade através da observação empírica e da indução, é, portanto, uma medicina baseada na evidência ${ }^{33}$. É neste domínio dos factos que a biomedicina acredita trabalhar (Rhodes, 1990: 160). Nesta conceção científica da medicina, apenas os médicos são competentes para fazer a tradução destes sinais e sintomas em entidades universais, que são as doenças. Por exemplo, uma doença como a tuberculose será sempre a mesma, em qualquer lugar em que ocorra, com a sua etiologia, o seu quadro clínico e o seu tratamento, sendo excluídas as suas dimensões psicológicas, sociais e culturais ${ }^{34}$.

Neste tipo de racionalidade científica, a verdade emerge, frequentemente, de uma certa mensurabilidade biologista ou, como refere Engel, a biomedicina baseia-se em normas de variáveis biológicas mensuráveis - o desvio é a doença (Engel, 1977: 130). De uma forma mais detalhada, Helman refere que "existe um uso crescente de definições numéricas para estados de saúde e de doença. A saúde ou a normalidade é definida pela referência a determinados parâmetros físicos e bioquímicos, tais como peso, altura, circunferência, contagem sanguínea, nível de hemoglobina, níveis de electrólitos ou hormônios, pressão sanguínea, ritmo cardíaco, ritmo respiratório, tamanho do coração ou acuidade visual" (Helman, 2003: 111). Para cada um

\footnotetext{
31 Neste artigo, "Medicalization and social control", P. Conrad faz uma recensão crítica da produção bibliográfica sobre o tema na década de setenta (Conrad, 1992). Veja-se também o texto de M. Lock, "Medicalization and the Naturalization of Social Control" (2003), no qual a autora, para além de traçar a história do conceito, apresenta diversos exemplos da medicalização, não apenas de comportamentos e aflições, mas também do bem-estar (Lock, 2003).

32 Relativamente às estratégias de tornar patológica a diversidade, mais especificamente a crítica à noção de "culture-bound syndromes", veja-se o artigo de C. Pussetti, "Patologização da Diversidade. Uma reflexão antropológica sobre a noção de culture-bound syndromes" (Pussetti, 2006).

33 Veja-se a revista Evidence-Based Medicine - for Primary Care and Internal Medicine, pertencente ao grupo BMJ (British Medical Journal), lançada em 1995. No caso português, veja-se o artigo do médico António Vaz Carneiro, com o elucidativo título: "A Medicina Baseada na Evidência - Um Novo Paradigma para a Prática Médica". O autor carateriza esta medicina da seguinte forma: "transforma os problemas clínicos em questões respondíveis e selecciona a evidência científica utilizando critérios e regras de avaliação crítica muito restritos e rigorosos" (Carneiro, 1997: 727).

34 Excluídas ficam também as dimensões históricas e metafóricas da doença. Ainda no caso da tuberculose, vejam-se as referências à dimensão metafórica da tuberculose no texto de S. Sontag, Illness as metaphor (1977) (Sontag, 1998, pp. 10-94). Relativamente à dimensão histórica da doença, veja-se na obra organizada por J. Le Goff, Les Maladies ont une Histoire (1985), o texto específico sobre a tuberculose de R-H Guerrand, “Guerra à tuberculose!” (Guerrand, 1997, pp. 187-201).
} 
destes itens existem balizas de normalidade, no exterior das quais aparecem sinais de anomalia, frequentemente traduzidos em doença.

Neste percurso de objetividade, a doença é vista como coisa (Queiroz, 2003: 122), como entidade independente do comportamento social (Engel, 1977). Através de um processo de reificação da doença, a doença adquire uma identidade própria, "com uma causa característica, um quadro clínico, resultados de investigações hospitalares, uma história natural, um prognóstico e um tratamento apropriado" (Helman, 2003: 111).

As invocadas objetividade, evidência e mensurabilidade remetem-nos para uma pretensa homogeneidade da biomedicina que, contudo, se reveste de heterogeneidades. Como afirma P. Worsley, "persistem diferenças culturais entre países que, teoricamente, subscrevem a 'mesma' medicina teórica Ocidental" (Worsley, 1997: 207). Podemos ver claramente isto no trabalho de Lynn Payer, Medicine and Culture, no qual é notória a variabilidade de tratamento e de diagnóstico de doenças, realizada por médicos em quatro países, França, Alemanha Ocidental, Inglaterra e Estados Unidos. Para além de sustentar que os cuidados de saúde, nos países estudados, são realmente pouco "baseados na evidência", L. Payer defende que os médicos, nos quatro países, praticam uma medicina muito diferente por causa da sua cultura e história nacional e a sua formação médica serem fundamentalmente diferentes (Payer, 1996). Se tomarmos como exemplo os medicamentos para o coração, L. Payer mostra que os alemães (ocidentais) tomam seis vezes mais medicamentos para o coração do que os franceses e os ingleses apesar da morte por doença cardíaca ser semelhante nos três países (Payer, 1996: 74); a pressão sanguínea considerada alta nos Estados Unidos, pode ser considerada normal em Inglaterra; na Alemanha Ocidental a pressão baixa é tratada com oitenta e cinco drogas, hidroterapia e em spas (Payer, 1996: 25).

Contudo, para além das variações culturais e sociais da medicina em diferentes sociedades, "mesmo dentro da mesma sociedade, diferenças enormes de perspectiva existem entre os diferentes ramos da medicina - entre (...) as perspectivas de cirurgiões, psiquiatras, epidemiologistas, médicos generalistas e especialistas em saúde pública" (Helman, 2003: 113). Podemos ir ainda mais longe, seguindo as ideias de Byron e Mary-Jo D. Good que consideram que "qualquer médico ou disciplina médica possui um repertório de modelos interpretativos - bioquímico, imunológico, viral, genético, ambiental, psicodinâmico, de interacção familiar, entre outros" (Good e Good, 1980: 177). Portanto, no limite, podemos ter cada médico com a sua singular perspetiva de diagnóstico e tratamento da doença.

Mas, mesmo esta perspetiva individual de interpretação e de tratamento da doença não se cristaliza no tempo, pois "as entidades patológicas, tais como a hipertensão, cancro ou doença coronária, são continuamente reavaliadas e retrabalhadas à medida que novas teorias etiológicas avançam e que novas técnicas de diagnóstico e tratamento são inventadas" (Helman, 2003: 113).

\section{Nota final: A biomedicina como um sistema cultural}

Culminando todo este percurso de caracterização crítica da biomedicina, conclui-se este texto com a afirmação da biomedicina como um sistema cultural. Para tal, torna-se imperativo, desde logo, olhar para o interior da própria antropologia para ver como é que estes investigadores situavam a biomedicina.

De facto, antes dos anos setenta, do século XX, mesmo os antropólogos consideravam a biomedicina, a medicina Ocidental, científica, como sendo de uma ordem totalmente diferente das medicinas de outras culturas não ocidentais, para as quais reservavam a designação de "etnomedicina" (Gaines, 2005). Tal como a ciência, a medicina era vista como acultural, ou seja, fora da influência da cultura, enquanto os outros sistemas, atendendo à sua reduzida ou nula "relevância científica", eram vistos como "tendenciosamente culturais" (Gaines e Davis-Floyd, 2004: 96). Aliás, a bitola científica, era apresentada como uma espécie de expressão da verdade que remetia para o campo da inverdade todos aqueles saberes que não utilizavam este tipo de conhecimento. Assim, a inferioridade de todos os outros saberes médicos que não trilham o caminho científico permite que a biomedicina possa catapultar-se para um nível superior às outras medicinas ou formas de cura e, como sugere Nettleton, reivindicar para si a competência de "oferecer a única resposta válida para compreender a doença e a enfermidade" (Nettleton, 1999: 3), denunciando intolerância relativamente às outras modalidades de cura (Davis-Floyd e St. John, 2001; Worsley, 1997).

Portanto, perante medicinas geograficamente distantes, que existem noutros contextos culturais, a biomedicina acultural situa-as na categoria de etnomedicinas; diante de medicinas geograficamente próximas, medicinas que se situam no mesmo contexto cultural, a biomedicina central situa-as na categoria de paralelas ou alternativas, entre outras designações.

Contudo, se por um lado a biomedicina se expandiu do Ocidente para outros contextos culturais ${ }^{35} \mathrm{e}$ medicinas oriundas de outros contextos culturais também elas migraram para o Ocidente, por outro, a 
superioridade da medicina Ocidental já não pode ser hoje tida como certa, da mesma forma que o era há um século atrás (Worsley, 1997: 217). De facto, para além das formas de combater a doença e promover a saúde que já existiam no Ocidente antes e durante a vigência da biomedicina, como o herbalismo e o recurso à Virgem e a santos curadores, a diversidade e complexidade de medicinas adensou-se no Ocidente. ${ }^{36} \mathrm{O}$ recurso crescente a uma panóplia alargada de medicinas decorreu seguramente de diversos fatores, como a incapacidade da biomedicina para tratar as doenças crónicas, algum receio dos efeitos secundários dos fármacos, o privilégio por terapias mais holísticas ou, mesmo, a insatisfação dos doentes com a comunicação com os médicos ${ }^{37}$.

Ao contrário da abertura que a biomedicina franqueou ao campo farmacológico, talvez por este se apresentar sempre como um contributo que serve sem pôr em causa a hierarquia da biomedicina, esta tem tido uma atitude de blindagem e homogeneização em relação à diversidade das outras medicinas que vivem no Ocidente ${ }^{38}$. Concomitantemente a não ser permeável a incursões de outras medicinas, reforçado o seu monopólio em todo o vasto campo da saúde, a biomedicina torna semelhante aquilo que é diferente, dando um mesmo nome a estas coisas, medicinas alternativas, paralelas, complementares, que pode variar no significante, mas que quase não varia no significado, são medicinas que gravitam em torno de um centro, a biomedicina, e em torno do qual se definem. Esta conceção da realidade da saúde, configura aquilo que propomos chamar etnocentrismo médico.

Esta doença de que padece o modelo biomédico começa, como refere Cristiana Bastos e Teresa Levy, desde logo, na formação dos médicos, pois é "nessa altura fundamental acreditar que aquilo que se estuda é a única forma de explicar a doença e promover a saúde" (Bastos e Levy, 1987: 221). Desta forma, o modelo biomédico é colocado no centro e todas as outras práticas curativas, profundamente heteróclitas entre si, são situadas numa dilatada e diversificada margem ${ }^{39}$. Portanto, aquilo que une estas medicinas não é a proximidade na explicação e tratamento da doença ou na promoção da saúde, pois o distanciamento entre algumas delas é enorme, aquilo que as une é apenas a sua condição de marginalidade relativamente à centralidade do modelo biomédico.

Em suma, foi preciso esperar pelos anos setenta, do século XX, para que, fomentadas pela antropologia (e também pela sociologia), fossem sendo reconhecidas as bases culturais das teorias e práticas biomédicas, permitindo ver a biomedicina como uma etnomedicina profissional e não como um padrão médico objetivo relativamente ao qual todos os outros sistemas são medidos (Gaines, 2005). Naturalmente que, como refere Nettleton, tal como outros sistemas, o sistema de crenças médicas está subordinado à sociedade que o produz (Nettleton, 1999: 7). Portanto, neste texto acompanha-se aquilo que foram defendendo diversos autores, nomeadamente Kleinman $(1973,1978,1981)$, que os sistemas médicos são social e culturalmente construídos, sendo um entre outros sistemas culturais como o de parentesco, o político ou o religioso. No fundo, a Biomedicina pode ser definida como um "sistema sociocultural" incluindo muitas variações, de "muitas medicinas" (Gaines e Hahn, 1985).

\footnotetext{
36 A diversidade é grande, ficam aqui apenas alguns exemplos: homeopatia, aromaterapia, acupuntura, cromoterapia, fitoterapia, terapia pela urina, flores de Bach, osteopatia, iridologia, entre diversos outros saberes médicos.

37 De facto, a insatisfação dos doentes é um dos maiores problemas de saúde (Kleinman, Eisenberg, e Good, 1978), mais especificamente a comunicação com os médicos, que se apresenta como a mais proeminente queixa dos doentes e o fator mais preponderante na procura de uma medicina alternativa, focalizada na boa e reconfortante comunicação e que concebe o doente como um participante informado no tratamento (Thompson, 1984: 87).

38 É interessante notar que apesar do distanciamento entre a biomedicina e outras estratégias de cura, o campo farmacológico parece criar formas de aproximação daquilo que ideologicamente era distante. Veja-se o exemplo do IMEPLAM do México. O Mexican Institute for the Study of Indigenous Medical Plants (IMEPLAM) faz regularmente uma listagem dos remédios à base de ervas usados pelas numerosas culturas indígenas do país e coloca nos seus computadores para atrair o interesse das indústrias farmacêuticas ocidentais que procuram o mais barato, eficaz e rentável medicamento semelhante ao mais utilizado de todos, a aspirina (desenvolvida a partir de casca de salgueiro) ou o medicamento cardíaco, a digoxina, desenvolvida a partir da dedaleira. Acrescente-se a este exemplo que mais de 7000 compostos médicos, que renderam, em 1985, 43 milhões de dólares, foram desenvolvidos a partir de plantas (Worsley, 1997: 227).

39 Como salienta Cristiana Bastos, as diversas práticas médicas marginais têm pouco em comum entre si, veja-se o caso das seguintes: ervanárias, mezinhas, bruxos, adivinhos, espíritas, endireitas, acupuntores ou iridologistas (Bastos, 1987: 223). Mais do que isto, mesmo dentro da mesma forma de cura há variações. Para além daquilo que já foi referido relativamente à biomedicina note-se, por exemplo, que também existem as diferenças entre a medicina ayurvedica do Sri Lanka e a medicina ayurvedica da Índia (Worsley, 1997: 220).
} 


\section{Bibliografía}

ARIÈS, Philippe

1989 [1975] “As atitudes perante a morte”. In Sobre a História da Morte no Ocidente desde a Idade Média. Lisboa: Teorema, pp. 17-66.

ARMSTRONG, David

1984 “The patient's view”. Social Science \& Medicine. Vol. 18, nº 9, pp. 737-744.

AUGÉ, Marc

1994 [1984] "Ordre biologique, ordre social: la maladie forme élémentaire de l'évenement". In AUGÉ, Marc ; HERZLICH, Claudine (org.) - Le Sens du mal: Anthropologie, histoire, sociologie de la maladie. Paris: Éditions des archives contemporaines, 35-91.

BARONOV, David

2008“Biomedicine: an ontological dissection”. Theoretical medicine and bioethics. 29(4), pp. 235-254.

2009"The Role of Historical-Cultural Formations within World-Systems Analysis: reframing the analysis of biomedicine in East Africa". American Sociological Association. Vol. XV, nº 2, pp. 147-166.

BERGER, Peter L. ; LUCKMAN, Thomas

1999 [1966]A Construção Social da Realidade: um livro sobre sociologia do conhecimento. Lisboa: Dinalivro.

BOLOGH, Roslyn Wallach

1981 "Grounding the alienation of self and body: a critical, phenomenological analysis of the patient in western medicine". Sociology of Health and Illness. Vol. 3, n 2, pp. 188-206.

CABRAL, João Pina ; FEIJÓ, Rui G.

1985"Um Conflito de Atitudes Perante a Morte: A Questão dos Cemitérios no Portugal Contemporâneo". In CABRAL, J. P. ; MARTINS, H. ; FEIJÓ, R. G. - A Morte no Portugal Contemporâneo - Aproximações Sociológicas, Literárias e Históricas. Lisboa: Querco, pp- 175-208.

CARAPINHEIRO, Graça

1993Saberes e Poderes no Hospital: Uma Sociologia dos Serviços Hospitalares. Porto: Afrontamento.

CARNEIRO, António Vaz

1997“A Medicina Baseada na Evidência: Um Novo Paradigma para a Prática Médica”. Acta Médica Portuguesa - Revista Científica da Ordem dos Médicos. No 8/9, II série, vol. 11, pp. 717-737.

CONRAD, Peter

1992“Medicalization and social control”. Annual Review of Sociology. 18, 209-232.

CSORDAS, Thomas J.

2010 [2001] "Os saberes da cura e a condição humana: cenas do momento presente em terras navajo". Educação, Porto Alegre, v. 33, n. 1, pp. 26-34, jan./abr.

DAVIS-FLOYD, Robbie E.

1992Birth as an American Rite of Passage. Berkeley: University of California Press.

2005 “On Birth”. Sage Encyclopedia of Anthropology. Lodon: Sage Publications.

DAVIS-FLOYD, Robbie ; St. JOHN, Gloria

2001From Doctor to Healer: The Transformative Journey. New Jersey: Rutgers University Press.

DESCARTES, René

1977 [1637]Discurso do Método. Lisboa: Europa-América.

DUBOS, René

1987 [1959]Mirage of Health: Utopias, Progress, and Biological Change. Nova Iorque: Rutgers University Press.

ENGEL, George L.

1977“The Need for a New Medical Model: A Challenge for Biomedicine”. Science. New Series, Vol. 196, $n^{\circ} 4286$ (Apr. 8, 1977), pp. 129-136.

FITZPATRICK, Ray

1984“Lay concepts of illness". In FITZPATRICK, Ray et al. - The Experience of Illness. Londres: Tavistock Publications, pp. 11-31.

FOUCAULT, Michel

1994 [1976] História da Sexualidade I - A vontade de Saber. Lisboa: Relógio D’Água. 
2002 [1974] “O nascimento do hospital”. In Microfísica do Poder. Rio de Janeiro: Graal, pp. 99-111.

2004-a [1980]O Nascimento da Clínica. Rio de Janeiro: Forense Universitária.

2004-b [1987]Vigiar e punir: nascimento da prisão. Petrópolis: Vozes.

FREUND, Peter E. S. ; McGUIRE, Meredith B.

1999Health, Illness, and the Social Body. New Jersey: Prentice-Hall.

GAINES, Atwood D.

1992"Medical/Psychiatric Knowledge in France and the United States: Culture and Sickness in History and Biology". Ethnopsychiatry: The cultural construction of Profissional and Folk Psychiatries. Nova Iorque: University of New York Press, pp. 171-201.

2005“Biomedicine”. In Encyclopedia of Anthropology. SAGE Publications. 14 Nov. 2008. <http://www. sage-ereference.com/anthropology/Article_n115.html>.

GAINES, Atwood D. ; DAVIS-FLOYD, Robbie

2004"Biomedicine”. In EMBER, Carol ; EMBER, Melvin (eds.) - Encyclopedia of Medical Anthropology - Health and Illness in the World's Cultures. Vol. 1, Yale, Human Relations Area Files, pp. 95-109.

GAINES, Atwood D. ; HAHN, Robert A.

1985“Among the Physicians: Encounter, Exchange and Transformation”. In HAHN, Robert A. ; GAINES, Atwood D. (eds.) - Physicians of Western Medicine: Anthropological Approaches to Theory and Practice. Dordrecht: Reidel, pp. 3-22.

GIDDENS, Anthony

2004Sociologia. Lisboa: Fundação Calouste Gulbenkian.

GODD, Byron ; GOOD, Mary-Jo Delvecchio

1980“The meaning of symptoms”. In EISENBERG, L. ; KELINMAN, A. (eds.) - The Relevance of Social Science for Medicine - culture, illness, and healing 1. Dordrecht: Reidel, pp.165-196.

GOFFMAN, Erving

1987 [1961]Manicómios, Prisões e Conventos. São Paulo: Perspectiva.

GUERRAND, Roger-Henri

1997 [1985]“Guerra à tuberculose!”. In LE GOFF, Jacques (org.) - As Doenças têm história. Lisboa: Terramar, pp. 187-201.

HELMAN, Cecil G.

2003Cultura Saúde \& Doença. Porto Alegre: Artmed.

HOFMANN, Bjørn

2002"Is there a technological imperative in health care?". International Journal of Technology Assessment in Health Care. 18:3, pp. 675-689.

ILLICH, Ivan

1977 [1975]Limites para a Medicina: A Expropriação da Saúde. Lisboa: Livraria Sá da Costa.

KLEINMAN, Arthur

1973“Some Issues for Comparative Study of Medical Healing”. International Journal of Social Psychiatry. $19,159-165$.

1978 "Concepts and a model for the comparison of medical systems as cultural systems". Social Science \& Medicine. Vol. 12, pp. 85-93.

1981Patient and Healers in the Context of Culture. Berkeley: University of Califórnia Press.

1995“What Is Specific to Biomedicine?". Writing at the Margin - Discourse between Anthropology and Medicine. Berkeley: University of California Press, pp. 21-40.

KLEINMAN, Arthur ; EISENBERG, Leon ; GOOD, Byron

1978“Culture, illness and care: Clinical lessons from anthropological and cross-cultural research". Annals of Internal Medicine. 88, pp. 251-258.

KOENIG, Barbara

1988“The technological imperative in medical practice: the social creation of 'routine' treatment". In LOCK, M. ; GORDON, D. (eds.) - Biomedicine Examined. Dordrecht: Kluwer, pp. 465-496.

LEWIS, Gilbert

1980"Cultural influences on illness behavior". In EISENBERG, L. ; KELINMAN, A. (eds.) - The Relevance of Social Science for Medicine - culture, illness, and healing. 1, Dordrecht: Reidel, pp.151152. 
LOCK, Margaret Lock

2003"Medicalization and the Naturalization of Social Control". In EMBER, Carol ; EMBER, Melvin (eds.) - Encyclopedia of Medical Anthropology: Health and Illness in the World's Cultures Topics. Volume 1 - Cultures, New York: Kluwer Academic/Plenum Publishers, pp. 116-125.

McKEOWN, Thomas

1976The modern rise of population. London: Edward Arnold.

McKEOWN, Thomas

1995 [1976]“"The medical contribution, cf. livro In DAVEY, Basiro ; GRAY, A. ; SEALE, C. (eds.) - Health and Disease: A Reader. Buckingham: Open University Press, pp. 182-190.

McKINLAY, John B. ; McKINLAY, Sonja M.

1977“The Questionable Contribution of Medical Measures to the Decline of Mortality in the United States in the Twentieth Century". Health and Society. Summer, pp. 405-429.

NETTLETON, Sarah

1999The Sociology of Health \& Illness. Cambridge: Polity Press.

OAKLEY, Ann

1986The captured womb: A history of the medical care of pregnant women. Oxford: Blackwell.

PAYER, Lynn

1996Medicine and Culture: Revised Edition. New York: Henry Holt and Company.

PFIFFERLING, John-Henry

1980“A cultural prescription of medicocentrism”. In EISENBERG, L. ; KELINMAN, A. (eds.) - The Relevance of Social Science for Medicine - culture, illness, and healing. 1, Dordrecht: Reidel, pp.197-222.

POWLES, John

1973“On the limitations of modern medicine”. Science, Medicine and Man. 1, 1, pp. 1-30.

PUSSETTI, Chiara

2006"Patologização da Diversidade. Uma reflexão antropológica sobre a noção de culture-bound syndromes". Etnográfica. Vol. X (1), pp. 5-40.

QUEIROZ, Marcos S.

1986“O Paradigma mecanicista da medicina ocidental moderna: uma perspectiva antropológica”. Revista de Saúde Pública. S. Paulo, 20(4), pp. 309-317.

1991"Perspectivas teóricas sobre medicina e profissão médica: uma proposta de enfoque antropológico". Revista de Saúde Pública. S. Paulo, 25(4), pp. 318-325.

2003Saúde e Doença. Um enfoque Antropológico. São Paulo: EDUSC.

RHODES, Lorna Amarasingham

1990“Studying Biomedicine as a Cultural System”. In JOHNSON, Thomas M. ; SARGENT, Carolyn F. - Medical Anthropology: Contemporany Theory and Method. Wesport: Praeger, pp. 159-173.

SCHEPER-HUGHES, Nancy ; LOCK, Margaret M.

1987“The Mindful Body: A Prolegomenon to Future Work in Medical Anthropology”. Medical Anthropology Quarterly, Mar., Vol. 1, 1, 6-41.

SONTAG, Susan

1998 [1977]“A Doença como Metáfora”. In A Doença como Metáfora e A Sida e as Suas Metáforas. Lisboa: Quetzal, pp. 10-94.

THOMPSON, James

1984“Communication with patients". In FITZPATRICK, Ray et al. - The Experience of Illness. Londres: Tavistock Publications, pp. 87-108.

WALDBY, Catherine

1997"The body and the digital archive: the Visible Human Project and the computerization of medicine". Health. Vol 1(2), pp. 227-243.

WORSLEY, Peter

1997Knowledges: Culture, Counterculture, Subculture. Nova Iorque: The New Press. 